\title{
Willy Mayer-Gross (1889-1961)
}

O ano de 2002 marcou o trigésimo aniversário da primeira tradução em português do livro Psiquiatria Clínica de Mayer-Gross, Slater e Roth (1976), que foi escrito quase integralmente por Mayer-Gross, tendo seus dois colaboradores contribuído com poucos capítulos e corrigido seu "inglês-alemão" (Peters, 1998). É possivelmente o único tratado de Psiquiatria Clínica escrito com o espírito da escola fenomenológica de Heidelberg, publicado no Brasil pela editora Mestre Jou, hoje desaparecida, e com tradução de Clóvis Martins Filho e Hilda Rosa. Esse livro, em dois elegantes volumes negros, durante muito tempo foi o porto seguro de toda uma geração de psiquiatras, contribuindo para uma virada na direção de uma psiquiatria clínico-fenomenológica na época áurea das correntes antipsiquiátricas das décadas de 1960 e 1970. Hoje, porém, injustamente caiu no esquecimento, tal como seu autor.

Wilhelm Mayer-Gross nasceu na cidade de Bingen (Renânia) em 15 de janeiro de 1889. Ao sobrenome paterno Mayer acrescentou, em época desconhecida, o sobrenome Gross, materno. Estudou Medicina em Heidelberg, Kiel e Munique, tornando-se assistente da Clínica Psiquiátrica de Heidelberg em 1912. Em 1913 defendeu seu doutorado "Sobre a fenomenologia dos sentimentos anormais de felicidade" (Zur Phänomenologie abnormer Glücksgefühle) (Willy Mayer Gross apud Peters, 1984 e 1998). Afastou-se para servir o exército na Primeira Guerra Mundial, retornando às suas funções em Heidelberg após o conflito. O período em que Mayer-Gross serviu o exército, primeiro no front durante um ano e, posteriormente, cuidando de um hospital para soldados com problemas psicológicos, colocou-o no meio de um debate nacional dos mais curiosos de sua vida e de toda a história da Psiquiatria. Até a Primeira Guerra, um relativo pluralismo era vigente no pensamento psiquiátrico da época, correntes científico-somáticas e psicológicas conviviam em paz. A pressão, porém, dos eventos colocou as abordagens médica e psicológica em campos opostos. A razão imediata foi o surgimento de uma neurose traumática específica, a neurose de guerra, que acabou por tornar-se tão comum que ameaçou os esforços de guerra da Alemanha. Assim como um ato de proteção nacional, neuróticos de guerra não eram considerados doentes nem tinham o beneplácito de serem protegidos e cuidados como doentes reais. $\mathrm{O}$ argumento era simples: se a histeria é um problema psicológico, não é uma doença; então, recursos médicos, mais do que inúteis, são indesejáveis (Fuscher-Homberger, 1975).

Mas, voltemos a Mayer-Gross. Em 1924 fez sua livre-docência com a tese Selbstschilderungen der Verwirrtheit ("Auto-relatos de estados confusionais"). Em 1929 tornou-se professor associado em Heidelberg. Junto com Beringer fundou a revista Nervenarzt e foi co-editor entre 1928 e 1934. Mayer-Gross trabalhou em Heidelberg inicialmente sob a chefia de Franz Nissl (1860-1919), que substituiu Kraepelin na Clínica Psiquiátrica, quando este se mudou para Munique para fundar o seu próprio instituto (Mayer Gross, 1998; FischerHomberger, 1975). Nissl era um professor bem ao gosto da época, como foram Paul Emil Flechsig, em Munique, e Carl Wernicke, em Breslau (e posteriormente em Halle), muito centrados em neuroanatomia e neuropatologia com pouco interesse e simpatia por uma abordagem psicopatológica dos fenômenos mentais, e até certo ponto niilistas quanto à possibilidade de tratamento dos pacientes 
psiquiátricos. A saída de Nissl em 1918, para assumir um posto que Kraepelin lhe ofereceu em Munique, e sua substituição na chefia por Karl Wilmanns, que chefiou a Clínica de 1918 a 1933, permitiu que Mayer-Gross e todo um grupo de jovens e promissores psiquiatras, como Karl Jaspers, Gruhle, Kronfeld, Wetzel, Beringer e Homburger, florescessem (Janzarik, 1979; Mundt, 1992).

Nos quase vinte anos que Mayer-Gross trabalhou em Heidelberg, seu segundo afastamento (após o período da Guerra) foi nos seis meses que passou com Bleuler no Hospital Burghölzli, da Universidade de Zurique, onde Bleuler foi professor de 1898 a 1927. O grande interesse de Bleuler pela psicanálise fez dele não apenas um homem interessado na compreensão psicológica da Demência Precoce nem apenas um colaborador e interlocutor das idéias freudianas, mas um incentivador da teoria psicanalítica entre seus alunos (Beauchesne, 1989). Carl Gustav Jung, Ludwig Binswanger e Karl Abraham, entre outros de seus alunos, tornaram-se psicanalistas, mas Mayer-Gross parece não ter se seduzido, mantendo uma postura crítica em relação à psicanálise pelo resto de sua vida. Aubrey Lewis, em seu trabalho sobre Mayer-Gross, agradece a oportunidade de ter passado meses em Heidelberg durante o ano de 1928, ao lado de Beringer (que o acolheu), do filosófico Jaspers, do hipercrítico Gruhle e do sempre entusiasmado Mayer-Gross (Lewis e Mayer-Gross, 1977).

Apesar da competência, o futuro de Mayer-Gross começou a ser ameaçado com a ascensão do nazismo. De fato sua sorte mudou muito antes de Hitler tornar-se Chanceler do Terceiro Reich, em 30 de janeiro de 1933. Já entre 1924 e 1926, quando da publicação de Mein Kampf ("Minha Luta"), sua sorte e a de tantos outros estavam seladas quando Hitler declarou que a sagrada missão do povo alemão "era reunir e preservar os maiores valores raciais (e)... paulatina mas firmemente assumir uma posição de domínio". E nesse mesmo livro estão contidas de maneira clara as sementes do anti-semitismo e do programa de esterilização de doentes mentais.

Apesar de ter sido convidado a assumir a cátedra de Psiquiatria de Groningen em 1932, sua origem judaica constituiu um obstáculo intransponível. Seus colegas e amigos alemães não-judeus também não tiveram saída. Alguns foram críticos e se opuseram tanto ao anti-semitismo quanto aos seus métodos, tais como: Karl Jaspers (cuja esposa era judia), Kurt Schneider, Karl Kleist, Karl Bonhoeffer (que assumiu ativa oposição, tendo seu filho Dietrich morto pelo regime), Oswald Bumke, Gerhard Creutzfeld e Ernst Kretschmer. De outro lado, Max de Crinis (sucessor de Bonhoeffer na cátedra de Berlim), Carl Schneider, Julius Deussen, Ernst Rudin, Werner Caterl e tantos outros foram entusiastas da nova Psiquiatria Nacional-Socialista (Lewis e Mayer-Gross, 1977). Carl Schneider, colega inclusive de Mayer-Gross em Heidelberg (e ainda eventualmente lembrado pelo sinal do "dedo em baioneta"), juntou-se ao Partido Nazista em 1932, assumiu a chefia da Clínica em 1933 e tornou-se um dos principais e mais ativos defensores dos programas de eutanásia (Lifton, 1986; Roelcke et al., 1998).

Parecia não haver saída até o momento em que o Commonwealth Fund of América conseguiu verba para que Mayer-Gross fizesse um clinical fellowship em Londres, no Maudsley Hospital e Bethlem Royal, para trabalhar com Edward Mapother. Nos anos seguintes, a Rockfeller Foundation ofereceu as facilidades econômicas para que outros psiquiatras judeus (como o psicogeneticista Franz Kallmann), bem como médicos de várias especialidades, emigrassem para outros países, particularmente os Estados Unidos e a Inglaterra. Entre os mais importantes no Maudsley Hospital, Aubrey Lewis (1977) destaca Eric Gutmann, Alfred Meyer e o próprio Mayer-Gross. Além desses, no ano de 1933 observou-se uma grande revoada de verdadeiros gênios abandonando a Alemanha, como o cineasta Max 
Ophuls, Boris Chain (prêmio Nobel de Medicina em 1945), Hans Gruneberg (geneticista), Norbert Elias (sociólogo) e mais Adorno, Bella Bartok, Bertold Brecht, Einstein, Freud, Thomas Mann, Karl Popper, Schoenberg... a lista é quase interminável (Ambrose, 2002). Apenas em 1933, cerca de 1.200 professores universitários judeus perderam seus empregos, cinco anos depois todas as 23 universidades alemãs eram "judenfre" ("livres de judeus") (Grady, 2002).

A mudança de Mayer-Gross para a Inglaterra, bem como o êxodo de grandes nomes da Psiquiatria alemã para outros países, deixou uma grande lacuna que demorou a ser novamente preenchida. Mais que o vazio técnico, ao fim da Guerra, Kretschmer e Kurt Schneider eram dos poucos grandes psiquiatras que se mantinham respeitados e capazes de servir de exemplo para a nova geração de estudantes (Häfner e Kretschmer, 1990).

Junto com a escola de Tübingen de Gaupp e principalmente as de Kretschmer e de Kraepelin, em Munique, a escola de Heidelberg, com o significativo reforço de Kurt Schneider foi a mais influente corrente do pensamento psiquiátrico europeu no período após a Segunda Guerra Mundial.

Durante o período que clinicou e lecionou em Heidelberg, foi um dos mais profícuos autores na área de psicopatologia, estudando os aspectos clínicos da esquizofrenia e os estados confusionais oniróides. Mayer-Gross foi, com seus estudos de evolução, um dos responsáveis pela mudança do pensamento de Emil Kraepelin, que acreditava na independência nosológica das parafrenias em relação à demência precoce.

O volume sobre esquizofrenia (1932) do Handbuch der Geisteskrankheiten ("Tratado dos Transtornos Mentais"), de Oswald Bumke (1932) - sucessor de Kraepelin em Munique -, de cerca de 800 páginas tem metade delas redigidas por Mayer-Gross.

Mayer-Gross foi um grande psicopatologista e um dos maiores psiquiatras clínicos de todos os tempos, aplicando com grande precisão e elegância o método fenomenológico desenvolvido por seu colega Karl Jaspers, bem como colaborando com grandes nomes da Alemanha de então, como Von Weizsacker, Max Weber, Gruhle e outros.

$\mathrm{Na}$ Inglaterra, enfrentando grandes dificuldades iniciais com a língua, trabalhou durante anos no Maudsley Hospital (1933-1939), ao lado do amigo e parceiro de pesquisas Erich Guttmann, no estudo das psicoses orgânicas, lesões cerebrais e insulinoterapia (Gruhle et al., 1960). Homem de interesses diversos, em 1937, Mayer-Gross escreveu a revisão do livro Kretische Kunst ("Arte Cretense”, de G. Snijder) para o Museu Arqueológico da Holanda, considerado naqueles dias, por diferentes autoridades, uma excelente tentativa de compreensão psicológica da arte minóica (Peters, 1998; Lewis, 1977).

Em 1939, foi designado para o posto de diretor de Pesquisa Clínica no Crichton Royal na Escócia, até ser aposentado compulsoriamente em 1955. Mesmo aposentado, tendo sofrido um infarto do miocárdio em 1949, transferiu-se em 1955 para o Departamento de Psiquiatria da Universidade de Birmingham, naquele momento recém-criado, onde foi Diretor de Pesquisa.

Após a guerra, teve o reconhecimento de sua importância nas mais reconhecidas universidades da Alemanha, tendo recebido o título de Professor Convidado em Munique e Hamburgo, bem como vários prêmios e homenagens da Organização Mundial da Saúde e na Inglaterra. Grato à terra que o acolheu, tornouse cidadão britânico e trocou seu prenome para Willy. Foi ainda um dos editores, junto com Gruhle, Jung e Müller, da primeira edição do tratado Psychiatrie der Gegenwart ("Psiquiatria Atual"), publicado em 1960 (Gruhle et al., 1960). 
Morreu em Birmingham, em 15 de fevereiro de 1961, quando se preparava, junto com sua mulher, para retornar a Heidelberg para reassumir seu posto. Ainda hoje, uma das enfermarias da Clínica Psiquiátrica da Universidade de Heidelberg recebe seu nome (URL: http://www.med.uni-heidelberg.de/psychia/ psychiatrie/stationen/konzepte/ mayergross/konzeptmayergross.htm).

O tratado Psiquiatria Clínica de Mayer-Gross, escrito em conjunto com E. Slater e Sir Martin Roth, teve sua primeira edição em 1954 e a segunda em 1960.

A terceira edição inglesa de 1969, traduzida para o português, traz uma homenagem, ao grande psiquiatra alemão, de seus co-autores, que reconhecem, entre outros méritos, o fortalecimento da Psiquiatria Clínica por Mayer-Gross em um momento em que a Psiquiatria inglesa estava mergulhada "nas generalidades improdutivas da psicobiologia de Adolph Meyer" (Slater \& Roth, 1976). Junto com o Textbook of Psychiatry de Henderson e Gillespie, foi das mais importantes publicações de Psiquiatria na Inglaterra (Moncrieff, 1999).

O texto, embora desatualizado nos aspectos etiopatogênicos e terapêuticos, traz minuciosas e ricas descrições da clínica e da psicopatologia dos transtornos mentais. Para aqueles que, felizmente, ainda não fizeram dos DSMs e CIDs seu livro-texto de Psiquiatria, o tratado de Mayer-Gross, Slater e Roth oferece um exemplo de rara e deliciosa leitura (ou releitura) psiquiátrica.

Táki Athanássios Cordás

Doutor em Psiquiatria pela Faculdade de Medicina da Universidade de São Paulo. Médico supervisor e coordenador geral do Ambulatório de Bulimia e Transtornos Alimentares (AMBULIM) do Instituto de Psiquiatria do Hospital das Clínicas da

Faculdade de Medicina da Universidade de São Paulo

Mario Rodrigues Louzã

Doutor em Medicina pela Universidade de Würzburg, Alemanha. Médico assistente e coordenador do Projeto Esquizofrenia (PROJESQ) do Instituto de Psiquiatria do HC-FMUSP

\section{Referências bibliográficas}

Ambrose, T. - Hitler's Loss: What Britain and America Gained from Europe's Cultural Exiles. Peter Owen (ed.), 2002.

Beauchesne, H. - História da Psicopatologia. Martins Fontes, São Paulo, 1989.

Bumke, O. (Hrsg.) - Handbuch der Geisteskrankheiten. Neunter Band, Spezieller Teil V. Die Schizophrenie. Spring Verlag, Berlin, 1932.

Fischer-Homberger, E. - Germany and Austria. In: Howells JG (ed.): World History of Psychiatry. Brunner/Mazel, New York, 1975.

Grady, T. - Academic Antisemitism: the Friedrich-Alexander University of Erlangen and the Jews. History Today 52(7): 48-53, 2002.

Gruhle, HW.; Jung, R.; Mayer-Gross W; Müller, M. (eds.). - Psychiatrie der Gegenwart. Springer, Berlin, 1960

Häfner, H.; Kretschmer, E. - 1888-1964. Psychol Med 20: 487-92, 1990.

JANZARIK, W. - 100 Jahre Heidelberger Psychiatrie. In: Janzarik W (ed.): Psychopathologie als Grundlagenwissenschaft. Enke Verlag, Stuttgart, 1979.

Lewis, A.; MAYer-Gross, W. - An appreciation. Psychol Med 7: 11-8, 1977.

Lifton, R.J. - The Nazi Doctors-Medical Killing and the Psychology of Genocide. Basic Books, New York, 1986.

Mayer-Gross, W.; Slater, E.; Roth, M. - Psiquiatria Clínica. Mestre Jou, São Paulo, 1976.

Meyer, J.E. - The fate of the mentally ill in Germany during the Third Reich. Psychol Med 18: $575-81,1988$.

MonCRIEFF, J. - An investigation into the precedents of modern drug treatment in psychiatry. Hist Psychiatry 10: 475-90, 1999. 
Mundt, CH. - The history of psychiatry in Heidelberg, In Spitzer, M.; Uehlein, F.; Schwartz, M.A.; Mundt, CH. (eds.): Phenomenology, Language \& Schizophrenia. Springer Verlag, New York, 1992.

Peters, U.H. - Mayer-Gross, W. (1889-1961), In: Schliack, H. \& Hippius, H. (Hrsg): Nervenärzte. Biographien. G. Thieme Verlag, Stuttgart, pp. 47-54, 1998.

Peters U.H. - Wörterbuch der Psychiatrie und medizinischen Psychologie. Urban \& Schwarzenberg, München, 1984.

Roelcke, V.; Hohendorf, G.; Rotzoll, M. - Hereditary psychological research in the context of "euthanasia": New documents and aspects on Carl Schneider, Julius Deussen and Ernst Rudin. Fortschr Neurol Psychiatr 66 (7): 331-6, 1998. 